\title{
Oligopoly with a large number of competitors: asymmetric limit result
}

\author{
Hiroaki Ino • Tomohiko Kawamori
}

Published online: 12 March 2008

(C) Springer-Verlag 2008

\section{Erratum to: Economic Theory DOI 10.1007/s00199-008-0344-x}

The original version of this article unfortunately contained a mistake. The presentation of Fig. 5 was incorrect. The corrected figure is given below.
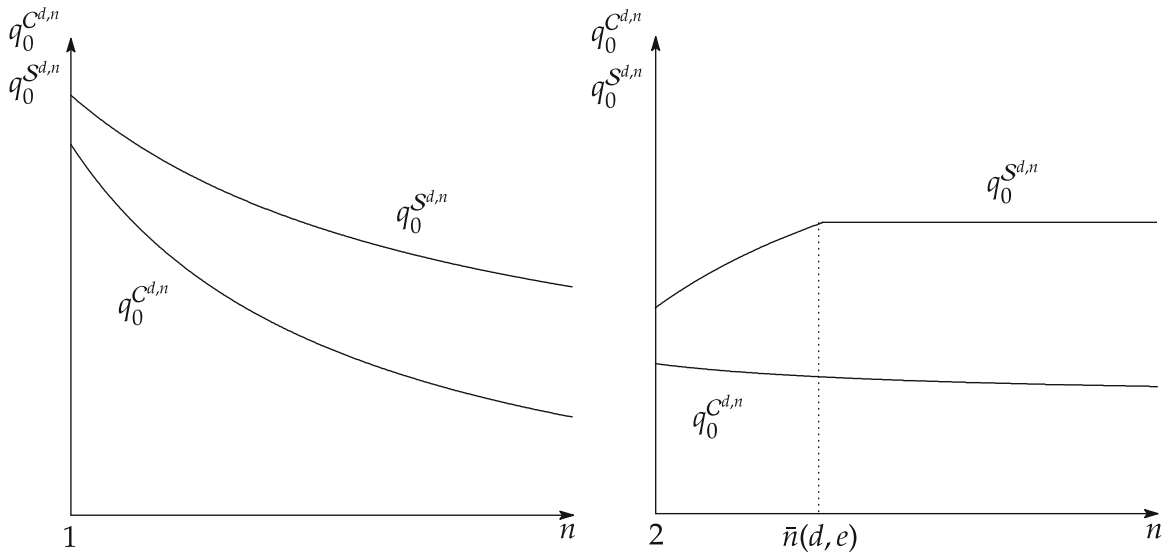

Fig. 5 Effect of the number of laggard firms on the innovator's equilibrium output. The left panel illustrates the case where $e=1$ and $d=\frac{1}{4}$. The right panel illustrates the case where $e=1$ and $d=\frac{17}{24}$

The online version of the original article can be found under doi:10.1007/s00199-008-0344-x.

H. Ino $(\varangle) \cdot$ T. Kawamori

Institute of Social Science, University of Tokyo, 7-3-1 Hongo, Bunkyo-ku, Tokyo 113-0033, Japan

e-mail: hiroakiino@04.alumni.u-tokyo.ac.jp

T. Kawamori

e-mail: ukawamor@mail.ecc.u-tokyo.ac.jp 